\title{
Efeito dos Incentivos Fiscais no Patrimônio das Entidades Beneficiárias do Programa FDI, do Governo do Estado do CeArÁ
}

Márcia Martins Mendes De Luca

Doutora em Contabilidade e Controladoria, Docente do Departamento de Contabilidade da FEAAC - Universidade Federal do Ceará marcia_deluca@hotmail.com

Virgínia Felício Lopes Lima Bacharel em Ciências Contábeis, Coordenadora Administrativa Financeira da Secretaria de Finanças de Fortaleza virginia_felll@hotmail.com

\section{RESUMO}

As mudanças ocorridas no cenário mundial nas últimas décadas impactaram, sobremaneira, o desenvolvimento dos países, contribuindo para a exacerbação das desigualdades regionais. No caso do Brasil, um país possuidor de grandes dimensões territoriais, a situação não poderia ser diferente, as disparidades regionais são imensas. O governo federal, na tentativa de corrigir essas desigualdades e promover um desenvolvimento econômico equilibrado entre as regiões, utiliza-se de algumas políticas, entre elas a concessão de incentivos fiscais. Complementarmente aos incentivos federais, os estados também utilizam políticas industriais próprias para alavancar seu desenvolvimento. No caso do Ceará, a política de incentivos consolidou-se com a criação do Fundo de Desenvolvimento Industrial - FDI. Esse trabalho tem como objetivo analisar o efeito dos incentivos fiscais no patrimônio das entidades beneficiárias, com foco nos programas subsidiados pelo FDI, através da análise das demonstrações contábeis da empresa Grendene S.A. Além da pesquisa bibliográfica e documental, foi realizada uma pesquisa aplicada às demonstrações contábeis da Grendene S.A. Constatouse com o estudo, a relevância da participação dos incentivos fiscais nos resultados da empresa, influenciando o desempenho dos seus indicadores econômicos e financeiros.

Palavras-chave: Incentivos Fiscais, Análise de Demonstrações Contábeis, Desenvolvimento Regional, Políticas de Investimento, Fundo de Desenvolvimento Intustrial.
ABSTRACT

Worldwide scenario changes in the last decades strongly affected the development of the countries, contributing to the increase of unbalanced regional differences. In Brazil, a large territorial dimension country, the status is not different: the regional disparities are also buge. The federal government, in an attempt to rectify such inequalities and to promote a balanced economic development among the regions, has implemented some policies, such as the concession of tax incentives. In addition to federal incentives, the states also use their own industrial polices to promote their development. In Ceara State, for instance, the policy of incentives was consolidated by the law of Industrial Development Fund FDI. This paper aims at analyzing the effect of tax incentives on the assets of the beneficiary entities, focusing on programs subsidized by FDI, through the analysis of the financial statements provided by Grendene $S$. A. In addition to the bibliographical and documentary research, a research applied to the company's financial statements was carried out. The study showed the relevance of tax incentives to the net income of such company, influencing the performance of its financial and economic indicators.

Key words: Tax Incentives, Financial Statement Analysis, Regional Development, Investment Policies, Industrial Development Fund. 


\section{INTRODUÇÃO}

No processo do desenvolvimento brasileiro, verificou-se um modelo concentrador de riquezas, constitucionalmente adotado ao longo de sua história. Vários fatores produziram desníveis regionais e se tornaram mecanismos promovedores de desigualdades sociais, dentre outros, desenvolvimento industrial tardio, ciclos econômicos desarticulados, desordenado processo de urbanização das cidades etc. Algumas regiões foram mais favorecidas que outras, marginalizadas em função de condições desfavoráveis, tanto geográficas quanto econômicas.

Com o objetivo de procurar reverter o quadro de segregação regional e promover uma justa divisão de riquezas, o governo federal tem lançado mão de políticas como as transferências de recursos para estados e municípios, criação de fundos regionais, bem como a concessão de incentivos fiscais.

A partir da década de 60 , ainda de forma tímida, os estados brasileiros passaram a formular e implementar políticas próprias de desenvolvimento industrial, complementarmente aos incentivos fiscais federais, estes mais relacionados com o imposto de renda. Com isso, passou a se instalar no território brasileiro o que se convencionou chamar "Guerra Fiscal", assim entendida como a disputa dos governos estaduais pela atração de indústrias.

No caso do Ceará, a política de incentivos fiscais consolidou-se a partir do final da década de 70 , quando foi criado o Fundo de Desenvolvimento Industrial - FDI, programa que desde sua implantação possibilitou a ampliação dos investimentos, provocando a instalação de diversas indústrias em território cearense, atraídas pela política de redução de carga tributária, o que por conseguinte, gera mais emprego e renda e no caso de empresas socialmente responsáveis, o melhoramento dos indicadores qualitativos do estado do Ceará.

Em um contexto macroeconômico, o bom desempenho do governo está intimamente ligado ao curso da atividade empresarial, onde esses elementos (Empresa e Estado) se inter-relacionam, um influenciando o outro. Nesse cenário, destaca-se a importância dos incentivos fiscais concedidos pelos governos federal e estadual, para as entidades beneficiárias desses incentivos, haja vista seus patrimônios serem diretamente afetados por essas variáveis, materializando-se nas demonstrações evidenciadas pela contabilidade.

O presente trabalho se propõe a mostrar os efeitos dos incentivos fiscais, com foco nos programas do FDI do governo do Estado do Ceará, no resultado das empresas beneficiárias, através da análise particular das demonstrações contábeis da empresa GRENDENE S.A.

Quanto à metodologia científica, utilizou-se no estudo o método dedutivo. Segundo as técnicas de pesquisa utilizadas, pode-se enquadrar o presente trabalho da seguinte forma: segundo os campos de atividade huma- na, enquadra-se como pesquisa multidisciplinar, pois envolve outras áreas de estudo além da contábil, como economia e finanças; segundo as técnicas e instrumentos de observações, utilizou-se a pesquisa bibliográfica e pesquisa documental; quanto ao critério de utilização dos resultados, o método que se adequa ao estudo é a pesquisa aplicada, através da realização de um estudo de caso para fundamentar o que se pretende mostrar.

O trabalho está estruturado da seguinte forma: inicialmente relacionam-se os principais tipos de incentivos utilizados pelos estados, com um breve comentário sobre a chamada "guerra fiscal". A seguir é apresentada a política de atração de investimentos do estado do Ceará, com foco no FDI/PROVIN (Fundo de Desenvolvimento Industrial / Programa de Incentivo ao Desenvolvimento Industrial), seu aperfeiçoamento ao longo de sua criação, seus critérios e metodologia de apuração. Por fim, apresenta-se um estudo de caso, baseado nas demonstrações da empresa GRENDENE S.A., onde se mostra o grau de relevância dos incentivos fiscais estaduais, principalmente os relacionados ao FDI/PROVIN nos seus resultados.

\section{OS INCENTIVOS FISCAIS CONCEDIDOS PE- LOS ESTADOS}

A partir dos anos 90, amparada pela descentralização promovida pela Constituição Federal de 1988 e da retomada do investimento propiciada pela estabilização da economia, verificou-se uma intensificação da prática de renúncias fiscais por parte dos estados federados, de forma que hoje esse instrumento é utilizado por praticamente todos os estados da federação.

A concessão de incentivos para atração de investimentos utilizados pelos governos estaduais, conforme explicita Rocha (2005), passou a ocupar papel mais relevante em suas estratégias de desenvolvimento, ainda que timidamente, a partir dos anos 60 , acompanhando a evolução histórica do País, quando a orientação da economia estava voltada para o desenvolvimento da atividade industrial.

Para Amaral Filho (2003), a concessão de benefícios fiscais justifica-se quando estes são concedidos proporcionalmente à defasagem na capacidade da localidade de melhor prover bens públicos e provados.

Segundo estudo realizado pela Confederação Nacional da Indústria (1998), em parceria com as Federações Estaduais de Indústrias e Secretarias Estaduais, destacase que os principais benefícios concedidos pelos governos estaduais às empresas industriais são de ordem fiscal, financeira e estímulos para infra-estrutura, conforme discriminado abaixo:

\section{BENEFÍCIOS FISCAIS:}

As principais concessões relativas aos incentivos de ordem fiscal são relacionadas a: a) Isenção de ICMS para 
novas empresas, sem produto similar no Estado e durante determinado período; b) Isenção ou redução do ICMS para micro e pequenas empresas; c) d) Redução de alíquotas de ICMS (para situações e produtos específicos); e) Prorrogação dos prazos de recolhimento do ICMS; f) Utilização do mecanismo de "diferimento" (recolhimento postergado); e g) Utilização do Crédito Presumido.

\section{BENEFÍCIOS FINANCEIROS:}

Muitos estados possuem como instrumento de política desenvolvimentista a formação de Fundos de Investimentos, cujos recursos, operados pelos bancos estaduais, são destinados a financiar programas e projetos com a finalidade de: a) Aquisição de ativos fixos; b) Formação ou recomposição de capital de giro; c) Pagamento do ICMS; e d) Composição acionária e debêntures conversíveis.

\section{ESTÍMULOS PARA INFRA-ESTRUTURA:}

Os principais suportes às indústrias promovidos pelos governos estaduais no que diz respeito à infra-estrutura são os seguintes: a) Venda de lotes e galpões industriais a preços reduzidos; b) Locação de lotes e galpões industriais, por prazo determinado; c) Permuta de terrenos para relocalização de empresas; d) Locação de máquinas e equipamentos; e e) Doação de áreas e lotes industriais (dependendo da natureza e capacidade de absorção de mão-de-obra do projeto).

Considerando os insuficientes esforços do Governo Federal em eliminar os desequilíbrios regionais, os Estados passaram a promover políticas mais atuantes objetivando o dinamismo e o crescimento de suas economias, utilizando como instrumento catalisador desse processo a concessão de incentivos fiscais. Como resultado dessas iniciativas, produziu-se uma situação de concorrência fiscal entre os estados da federação, evoluindo para o que hoje se convencionou chamar "Guerra Fiscal".

\section{- Os incentivos fiscais estaduais e a "Guerra Fis- cal"}

A Guerra Fiscal, como o próprio nome sugere, reflete uma situação de disputa no âmbito da federação, verificada quando dois ou mais estados passam a competir entre si visando atrair empresas para seus territórios, mediante a concessão desmedida de incentivos de ordem fiscal e financeira.

Em condições normais, a concessão de incentivos não constitui um problema, ao contrário, contribui para ajustar a desvantagem de determinados estados, marginalizados no processo de desenvolvimento da nação, haja vista que, uma vez instalada em uma região, a atividade industrial movimenta a economia local, gerando mais empregos e impactando diretamente fatores como produção e renda.
Portanto, responsavelmente geridos, os incentivos fiscais se consolidariam em uma política eficaz de combate às desigualdades regionais. Entretanto, o que hoje se observa é uma distorção do caráter equalizador desses instrumentos, promovido pela concorrência irracional entre os Estados na briga pela atração de investimentos. A problemática deriva do fato dos demais governos copiarem a experiência bem sucedida de um determinado estado, deflagrando a Guerra Fiscal.

Para Varsano (1997), instaurada a guerra, todos perdem. Para começar, perdem os próprios estados que dela participam. Como todas as localidades oferecem mais ou menos os mesmos benefícios, os estados mais ricos partem na frente na corrida pela atração de indústrias, pois estas tendem a se instalar nas regiões que ofereçam melhores condições em termos de infra-estrutura e mercado, condições na maioria das vezes satisfeitas por esses estados.

Os efeitos negativos da guerra fazem-se sentir também pelas empresas não contempladas pelas benesses fiscais. Sentindo-se prejudicadas em relação às empresas detentoras de incentivos, elas passam a pressionar o governo, pleiteando as mesmas condições para que possam disputar o mercado em condições de igualdade. E assim as receitas tributárias vão-se esvaindo dos cofres públicos, acabando o Estado por perder a capacidade de oferecer infra-estrutura necessária ao capital privado, pois as finanças públicas são comprometidas de maneira relevante, tornando o governo local dependente das transferências de recursos da União.

Em longo prazo, os efeitos nocivos dessa prática se estendem até chegar o estágio dos incentivos fiscais perderem seu poder de estímulo, pois as empresas passam a orientar suas decisões estratégicas apenas em função de fatores econômicos, que incluem a qualidade de infraestrutura e dos serviços públicos oferecidos, haja vista as condições tributárias oferecidas pelos estados serem praticamente as mesmas aonde quer que elas decidam se instalar. Dessa forma, os incentivos deixam de ser critério que pesa na decisão de localização e a guerra fiscal acaba por punir os estados mais pobres, que se utilizam dessa concessão exatamente para tornar sua oferta de serviços mais atraente.

Do ponto de vista social, os cidadãos também são afetados. A concessão de incentivos implica em renúncia de receita que poderia ser utilizada pelo poder estadual para oferecer aos seus residentes, melhores condições de vida. Com a renúncia, o governo fica com margem menor para investir em segmentos considerados prioritários como educação e saúde.

\section{A POLÍticA DE INCENTIVOS FISCAIS DO CEARÁ}

Ocupando um território correspondente a 145.711,8 $\mathrm{Km}^{2}$, o Ceará está localizado em uma área privilegiada, 
próxima aos grandes mercados consumidores da Europa e América do Norte, fato que lhe confere determinadas vantagens competitivas em termos de logística e que tem contribuído para a atração de diversas indústrias que optaram por se instalar em seu território nos últimos anos.

A formulação de políticas desenvolvimentistas, que no Brasil teve início a partir dos anos 50 , no Ceará só começou a ser posta em prática na década seguinte, em 1963 com a instituição do PLAMEG - Plano de Metas Governamentais. Este foi o primeiro passo para uma série de outros planos, como por exemplo, o PLAIG - Plano de Ação Integrada do Governo, o PLAGEC - Plano de Governo do Estado do Ceará e o I PLANDECE - I Plano Qüinqüenal de Desenvolvimento do Estado do Ceará, que procuraram dar continuidade às metas iniciadas pelo PLAMEG, promovendo estímulos às empresas industriais. O Fundo de Desenvolvimento Industrial (FDI) foi criado em 1979, através da Lei 10.367.

\section{- O FDI}

A criação do FDI representou um marco na política de incentivos para a indústria no Ceará. Desde sua vigência, a legislação do FDI passou por diversas reformulações ao longo do tempo. Na década de 90 , as mudanças foram orientadas no sentido de dar maior ênfase à consolidação do Parque Industrial do Estado. Para tanto, estimulouse a desconcentração espacial, incentivando projetos a serem implantados fora da Região Metropolitana de Fortaleza (RMF). O teto para os empréstimos concedidos seria de $60 \%$ do ICMS para os empreendimentos a serem instalados na RMF e 75\% para aquelas empresas que se instalassem fora da RMF. Os incentivos também se davam em função do prazo de gozo. Empresas que optassem localizar-se a mais de $500 \mathrm{~km}$ da RMF poderiam gozar do benefício por até 180 meses. Aquelas a serem localizadas a menos de $300 \mathrm{~km}$ tinham o prazo do benefício fixado em 120 meses, enquanto plantas industriais a serem instaladas na RMF gozariam do benefício por 72 meses. Poderiam pleitear o benefício, as indústrias "consideradas de fundamental interesse para o desenvolvimento econômico do Estado" (Lei 10.367, Art $2^{\circ}$ ), sendo definidas posteriormente como aquelas que a) contribuíssem para a absorção intensiva de mão-de-obra; b) utilizassem de forma preponderante matéria-prima local; c) produzissem bens sem similar no Estado; e d) contribuíssem para a substituição de importações.

A partir de 2002 verifica-se um novo modelo de política industrial no Ceará. Para corrigir algumas incoerências na concessão de incentivos, que estavam provocando estrangulamentos nas finanças do Estado e pela ineficácia no sentido de combater a concentração industrial na RMF, o governo estadual promoveu uma revisão dessas políticas introduzindo significativas alterações na orientação e filosofia do FDI. Assim, a concessão de incentivos foi reformulada, passando a ser, a partir de en- tão, mais seletiva em seus critérios, ampliando seu objetivo de ser apenas uma política de atração de investimentos para se destinar a promover o desenvolvimento do estado de maneira mais responsável, através do apoio à atração de empreendimentos considerados essenciais para a formação de aglomerações industriais - cadeias produtivas e atividades estratégicas para o fortalecimento do empreendedorismo (SDE, 2005).

Para tanto os incentivos passaram a ser concedidos em função das cadeias produtivas, já existentes ou em formação. A proposta era incentivar prioritariamente aqueles empreendimentos que viessem a fazer parte de uma cadeia, aumentando a competitividade entre as empresas. Com isso o governo buscou combater a dependência gerada pelos incentivos, pois, no longo prazo, com o fortalecimento desses aglomerados, concedê-los se tornaria aos poucos desnecessário.

Em 2003, a Lei 13.377, de 29 de setembro de 2003, trouxe novas alterações na sistemática de operacionalização dos incentivos fiscais: os incentivos concedidos anteriormente eram realizados sob a forma de empréstimos subsidiados pelo estado do Ceará. A referida Lei e o Decreto 27.206, de 07 de outubro de 2003, que a regulamentou, modificaram essa sistemática que passou a consistir no DIFERIMENTO de uma percentagem do saldo devedor do ICMS, com dedução de uma parcela do montante diferido, no caso de pagamento do débito até a data de vencimento do diferimento.

A partir de 2004, o Decreto 27.470, de 16 de junho de 2004, estabeleceu uma sistemática alternativa à concessão de incentivos fiscais do PROVIN previstos na Lei 13.377. Pela referida norma, o Estado do Ceará poderá ceder ao FDI a título oneroso e nos termos estabelecidos no Convênio 104/02, celebrado no âmbito do CONFAZ, os direitos creditórios oriundos da parcela do ICMS cujo prazo de pagamento tenha sido diferido conforme determina a Lei $13.377 / 2003$. As empresas interessadas em aderir à nova sistemática devem assinar um termo de acordo e apresentá-lo ao BEC (Banco do Estado do Ceará, agente financeiro do FDI).

Os tópicos seguintes se propõem a melhor caracterizar o FDI, sua finalidade, seus programas e critérios.

\section{I) Caracterização:}

Conforme Decreto 27.040, de 09/05/2003, a política de desenvolvimento industrial do Ceará é mantida pelo Fundo de Desenvolvimento Industrial - FDI, cuja finalidade compreende: I - Ações voltadas para atração seletiva de inves-
timentos industriais, visando à formação e o
adensamento das cadeias produtivas selecionadas
e a formação de aglomerações espaciais;
II - Disponibilidade de infra-estrutura necessária
para implantação e pleno desenvolvimento da 
atividade produtiva;

III - Apoio e indução ao desenvolvimento industrial objetivando:

a) O fortalecimento da rede de instituições voltadas para o desenvolvimento sócio econômico e a absorção e disseminação de novas tecnologias;

b) $\mathrm{O}$ fomento do empreendorismo, com ênfase no segmento de micro e pequenas empresas;

c) A atração e o fortalecimento de empresas locais de base tecnológica;

d) A geração e o incremento de cadeias produtivas.

IV - Treinamento e capacitação de mão-de-obra.

Para consecução de seus objetivos o Fundo de Desenvolvimento Industrial do Estado do Ceará concede às empresas beneficiárias incentivos para implantação, ampliação, diversificação, e recuperação de estabelecimentos industriais, por meio de programas aprovados pelo Conselho Estadual de Desenvolvimento Industrial (CEDIN), por proposição da Secretaria de Desenvolvimento Econômico - SDE (Art $4^{\circ}$, Dec 27.040).

Relativamente ao ICMS, os incentivos são concedidos sob a forma de (Incisos IV e V do Art $5^{\circ}$, da Lei 13.377, de 29 de setembro de 2003):

IV - A concessão de incentivos fiscais relativos ao ICMS, através:

a) da dilatação do prazo de pagamento de parcela do saldo devedor mensal do imposto, com dedução do percentual dessa parcela, no caso de liquidação do débito até a data do vencimento da dilatação;

b) do diferimento do momento de pagamento total ou parcial do imposto, com dedução de percentual total ou parcial do montante diferido, no caso de liquidação do débito até a data do vencimento do diferimento;

c) da concessão de crédito fiscal presumido e de redução da base de cálculo do imposto.

$\mathrm{V}$ - A concessão de incentivos financeiros relacionados ao ICMS, com a concessão de empréstimos, a médio e longo prazos, inclusive com subsídios sobre o principal e encargos financeiros.

A operacionalização do Fundo de Desenvolvimento Industrial está a cargo do Banco do Estado do Ceará S.A. (BEC), da Secretaria de Desenvolvimento Econômico (SDE) e do Conselho Estadual de Desenvolvimento Industrial (CEDIN).

Para sua formação o FDI conta com quatro fontes de recursos: 1) os de origem orçamentária; 2) empréstimos ou recursos a fundo perdido oriundos da União, Estado e outras entidades; 3) contribuições, doações, legados e outras fontes de receitas; e 4) receitas decorrentes da aplicação de seus recursos.

\section{II) Programas}

O Quadro 1 mostra alguns dos Programas do Fundo de Desenvolvimento Industrial (FDI).

\begin{tabular}{|c|c|}
\hline Programas & Descriçáa e Objetwo \\
\hline FDI $/$ PDCI & 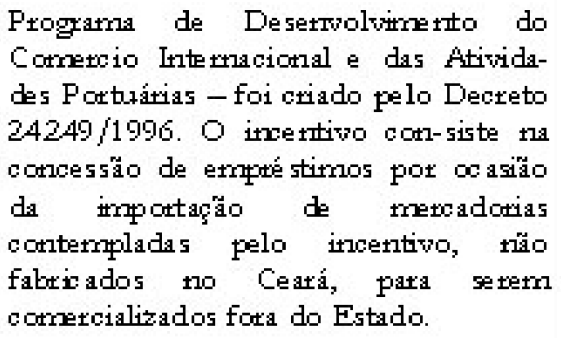 \\
\hline FDI / PROCAF & 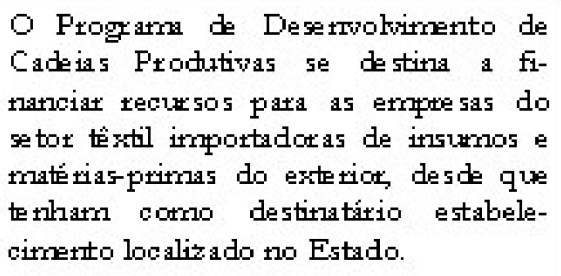 \\
\hline FDI / PROTIN & 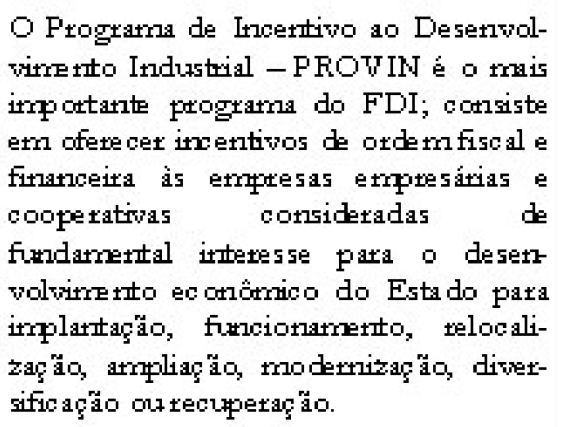 \\
\hline
\end{tabular}

Quadro 1: Programas do Fundo de Desenvolvimento Industrial Fonte: elaborado a partir de SDE - Guia do Investidor (2005)

Quanto ao FDI / PROVIN, as empresas poderão gozar dos benefícios desde que obedeçam alguns critérios, a saber:

\section{a) Critérios de Habilitação}

Conforme Decreto 27.040/2003, os critérios a que devem se enquadrar os candidatos ao benefício, dividemse em: volume de investimento, setor e cadeia produtiva a que pertence o investimento, geração de emprego, impacto sobre a demanda por matérias-primas, insumos e serviços locais, localização geográfica do empreendimento, responsabilidade social, cultural e ambiental. Para cada critério, existe uma pontuação de acordo com a aplicação da empresa e de seu investimento. Cada ponto corresponderá a 1 ponto percentual de benefício e o benefício mínimo é de $25 \%$. A soma dos pontos máximos de todos os itens deverá atingir 50 pontos e determinará 
o prazo dos benefícios (máximo de 10 anos) e o valor dos retornos $(15 \%$ a $25 \%)$.

Após a fase de habilitação é elaborado um protocolo de intenções firmado entre a empresa e o governo do estado, onde se oficializa a efetivação da implantação do empreendimento e do enquadramento no programa.

\section{b) Limites para concessão}

A concessão dos incentivos está limitada a 75\% e o limite mínimo é de $25 \%$. Os limites de retorno do valor concedido a título de empréstimo, ou seja, o valor financiado pelo governo que efetivamente será recolhido pela empresa após o período de carência, varia conforme a pontuação atribuída ao projeto, devendo ser respeitado o limite mínimo de $10 \%$ e máximo de $25 \%$.

\section{c) Prazo e carência do benefício}

O período de carência do empréstimo é de 36 meses, sendo corrigido pela Taxa de Juros a Longo Prazo (TJLP) e o prazo do benefício é de no mínimo 05 anos e no máximo 15 anos.

\section{d) Localização Geográfica}

A empresa candidata ao benefício poderá escolher livremente a localização geográfica em território cearense, entretanto, será atribuída uma maior pontuação àqueles empreendimentos que se localizarem fora da RMF.

\section{e) Metodologia}

O incentivo concedido pelo FDI / PROVIN consiste, em resumo, na concessão de empréstimo, cujo valor é determinado pela dedução de uma percentagem (fixada no protocolo de intenções) sobre o montante do valor do ICMS apurado mensalmente pelo estabelecimento, ou seja, o valor do empréstimo é realizado com base no Livro de Apuração do ICMS, que será pago após um período de carência (também determinado após aprovação da planta).

A empresa goza do incentivo à medida que se beneficia da renúncia fiscal concedida pelo estado, o qual renuncia uma parte do empréstimo (que será determinada conforme pontuação que o projeto obteve, sendo que o retorno aos cofres públicos deverá ser de no mínimo 10\% do valor financiado).

Cabe ressaltar que somente serão objeto de dedução, as vendas de produção própria do estabelecimento, portanto deverão ser adicionados ao valor do ICMS mensal a pagar as vendas de mercadorias adquiridas de terceiros e quaisquer outros valores que não corresponderem às operações próprias da empresa.

\section{f) Outras Considerações}

Apesar de passar por contínuos processos de aperfeiçoamento desde sua criação, o FDI ainda é objeto de discussões. Um dos pontos merecedores de questionamento é o relevante volume de recursos renunciados pelo estado em prol do desenvolvimento e manutenção das empresas beneficiárias, o que nos leva a também questionar o perfil das empresas beneficiárias dos programas financiados pelo FDI.

Como a concessão de incentivos fiscais implica em renúncia de receita que poderia ser utilizada para promover o bem estar social, entra em foco a responsabilidade social das empresas que são beneficiárias do programa, pois estas deixam de dar a sua contribuição ao governo, através do pagamento do ICMS, os quais são renunciados, muitas vezes em montante maior do que o devido, pelos governos estaduais.

Nesse contexto cabe discutir o perfil das empresas que a política de incentivos do estado do Ceará têm beneficiado, se àquelas empresas isentas de atitudes que visem o desenvolvimento regional ou se àquelas que efetivamente tem procurado cumprir seu papel social, tornando-se parceiras do governo na busca do desenvolvimento econômico, inclusive assumindo o compromisso que firmaram com o governo ao assinarem o protocolo de intenções com o Estado / Município em que se encontram instaladas.

\section{ANÁLISE DAS DEMONSTRAÇÕES FINANCEI- RAS DA EMPRESA GRENDENE S.A.}

O objetivo deste trabalho é mostrar o efeito dos incentivos fiscais, no âmbito do Programa FDI, no patrimônio das entidades beneficiárias. Para demonstrar o que se pretende, estudar-se-á o caso da empresa Grendene S.A.

A escolha da Grendene deveu-se ao seu papel de destaque no setor calçadista, bem como ao fato dela ser beneficiária do FDI e de seus programas PROVIN e PROAPI.

Os dados analisados no estudo foram retirados do prospecto que a empresa publicou em outubro de 2004 (disponível em seu site www.grendene.com.br), em virtude da abertura de capital, com o intuito de dar subsídios aos investidores interessados em comprar suas ações, como também das demonstrações financeiras relativas ao exercício de 2004. O referido documento contém dados societários e financeiros da empresa, acompanhados do parecer dos auditores.

O estudo consiste em analisar o impacto dos incentivos fiscais estaduais no patrimônio da empresa e o grau de relevância desses incentivos no seu resultado, principalmente no âmbito do programa FDI, através da análise particular das demonstrações financeiras da Grendene S.A. Registra-se a limitação do estudo devido à análise dos dados contábeis dos anos de 2002, 2003 e 2004. Não foram analisadas outras formas de captação de recursos como alternativa à utilização dos incentivos fiscais. 


\subsection{Caracterização da empresa}

A empresa Grendene S.A. desenvolve, fabrica e comercializa calçados sintéticos de PVC e EVA. Dona de marcas nacionalmente conhecidas como as linhas Rider, Melissa e Grendha, a companhia figura entre as principais empresas do ramo de calçados do Brasil. Em 2004, foi eleita pela revista EXAME, em sua edição Melhores \& Maiores, a melhor companhia do setor industrial de confecções, têxteis e calçados. Sua posição de destaque foi ainda divulgada na edição de 2004 do Prêmio Delmiro Gouveia, onde a empresa aparece em $4^{\circ}$ lugar entre as maiores empresas do estado do Ceará e a maior nas categorias resultado final líquido e quantidade de empregados.

Sua produção é destinada aos mercados interno e externo. As vendas do mercado externo são realizadas através de empresas controladas do grupo no Uruguai, Argentina e Estados Unidos e representaram, no ano de 2003, 24\% do faturamento bruto da companhia.

Em operação desde 1971, a empresa iniciou suas atividades inicialmente no Rio Grande do Sul, na cidade de Farroupilha. Apenas em 1993 transferiu o centro de produção para o estado do Ceará (a unidade de Farroupilha continua a existir, mas abriga principalmente os centros administrativo, comercial e de marketing) motivada primordialmente, segundo informações da própria companhia, pela concessão por parte do governo estadual de benefícios fiscais e da localização geográfica estratégica, próxima aos mercados consumidores de seus produtos exportados.

Atualmente suas plantas industriais no Ceará localizam-se, além das instaladas na cidade de Farroupilha e Carlos Barbosa (RS), nos municípios de Sobral (a maior no estado em termos de produção, que conta com uma área ocupada de aproximadamente 154 mil metros quadrados) e Crato, inaugurada em 1997. Em Fortaleza estão duas de suas unidades, as quais produzem linhas de calçados manufaturados.

\subsection{Os incentivos fiscais estaduais de titularidade da empresa}

A companhia goza de incentivos fiscais através de dois programas do FDI: o PROVIN e o PROAPI.

\section{- PROAPI}

O Programa de Incentivos às Atividades Portuárias e Industriais - PROAPI foi instituído em 1995 como um incentivo às exportações de empresas calçadistas, instaladas no estado. Compreende em um financiamento de 6\% sobre o valor FOB das exportações realizadas por empresas do setor de calçados, beneficiárias do programa, situadas na Região Metropolitana de Fortaleza e de
$11 \%$ para aquelas situadas fora da RMF, com recursos advindos de operações de crédito de FDI. Por tratar-se de um subsídio à exportação, considerando que essa prática é alvo de críticas por parte do governo e pelo fato de não ter contribuído de maneira significativa para o desenvolvimento industrial do estado, o PROAPI não está mais em vigor.

Apesar de atualmente extinto, as empresas que tiveram seus projetos aprovados pelo estado para fazer jus aos incentivos disponibilizados pelo PROAPI, continuaram a ter o direito de usufruir seus benefícios.

A Grendene é titular dos incentivos do PROAPI em duas de suas unidades, Sobral e Crato. Às duas unidades, o FDI disponibiliza um financiamento correspondente a $11 \%$ do valor FOB das exportações, com retorno de $10 \%$ do total do montante financiado em 60 meses. A vigência dos incentivos do PROAPI para a filial de Sobral vai até 2011, enquanto para a do Crato até 2014.

Conforme informação da empresa, o governo do estado não tem liberado regular e integralmente os valores contratados previstos no contrato de mútuo referentes aos benefícios do PROAPI. Em 2003 deixou de receber aproximadamente 2,9 milhões de reais e até 30 de junho de 2004, 3,4 milhões de reais.

\section{- PROVIN}

A sistemática de operacionalização do PROVIN já foi explicada em tópicos anteriores. A Grendene é titular de seus benefícios nas seguintes condições:

- A unidade de Sobral, conforme contrato de mútuo em vigor até 2009 , é incentivada com financiamento correspondente a $100 \%$ do valor do ICMS apurado mensalmente. Do valor financiado deverá desembolsar após 60 meses o correspondente a $25 \%$. O prolongamento do benefício está assegurado até 2019, pois a empresa já assinou aditivo com o governo do Estado. As condições acordadas estabelecem que os empréstimos serão de $75 \%$ do valor do ICMS apurado mensalmente, sendo que, do montante financiado a empresa deverá pagar ao governo do estado, após o prazo de carência fixado em 36 meses, o percentual de $1 \%$

- A sede de Fortaleza conta com incentivos do PROVIN fixado em $75 \%$ do ICMS apurado no mês com taxa de retorno de $1 \%$ sobre o valor total financiado a pagar em 36 meses. A vigência do incentivo vai até 2015.

- A filial do Crato é titular dos benefícios até 2012 . O estado do Ceará assegura empréstimos mensais de 75\% baseados no valor apurado do ICMS. No decorrer de 60 meses a empresa deverá pagar 1\% do valor total financiado.

O gozo da renúncia fiscal do estado está vinculado ao pagamento nos prazos acordados em contrato, bem como ao cumprimento de determinadas obrigações. Caso a empresa não pague os empréstimos na data de vencimento ou não cumpra qualquer das condições previstas, 
estará sujeita a pagar o valor total disponibilizado a título de financiamento.

Em seu prospecto, a companhia faz algumas ressalvas referentes às operações da empresa no âmbito do PROVIN.

Conforme o referido documento, a Companhia poderá ter, dependendo de decisão que lhe seja desfavorável, os benefícios decorrentes do PROVIN cancelados e/ou ser cobrada por valor correspondente ao objeto do financiamento. A empresa informa ainda que o procedimento atualmente adotado pela companhia poderá não ser mantido no futuro ou, caso venha a ser alterado, não contemplar condições favoráveis à entidade.

Segue resumo dos benefícios da empresa no âmbito estadual: ajustes na Demonstração do Resultado do Exercício, com a finalidade de permitir a comparabilidade das demonstrações financeiras:

- Em 2003 foram adicionados os valores relativos aos benefícios fiscais anteriormente lançados na conta de reserva de capital, no valor de $\mathrm{R} \$ 63.707$ milhões ( $\mathrm{R} \$$ 42.994 relativos aos incentivos PROVIN e PROAPI e R\$ 20.713 referentes ao IR), bem como a demonstração foi ajustada pelos valores relativos às provisões e outros valores.

- Em relação a 2004, tendo em vista que o prospecto só contempla valores até o mês de junho, bem como para permitir a compa-rabilidade da análise da DRE ajustada em 2003, foram efetuadas as devidas alterações de provisões não contempladas, bem como dos benefícios fiscais auferidos no ano ( $\mathrm{R} \$ 113.203$ milhões), com base nas informações constantes em notas explicativas relativas às demonstrações financeiras do ano de 2004 publicadas pela empresa.

Foram utilizadas as demonstrações pró-forma para que a análise seja mais próxima da realidade financeira da empresa. No final deste trabalho são apresentadas algumas das demonstrações contábeis da Grendene.

Os valores referentes somente ao FDI foram extraídos de notas explicativas e da Demonstração das Mutações do Patrimônio Líquido (DMPL) e se encontram dispostos da seguinte forma:

- Em 2002, foi registrado um incremento patrimonial relativos às parcelas incentivadas desses financiamentos no valor de $\mathrm{R} \$ 52.564$ milhões.

- Em 2003, foi registrado um incremento patrimonial de $\mathrm{R} \$ 78.277$ milhões, $\mathrm{R} \$ 35.283$ milhões no patrimônio líquido da controlada Grendene Calçados S.A., no período de $01^{\circ}$ de janeiro a 31 de julho de 2003, reconhecidos na controladora GRENDENE S.A. como resultado de equivalência patrimonial e R $\$ 42.994$ milhões no patrimônio líquido da GRENDENE S.A., referente ao período de 01 de agosto a 31 de dezembro de 2003. Em 2004, foi registrado o valor de $\mathrm{R} \$ 93.155$ milhões apenas relativos ao FDI.

No anexo A são apresentadas algumas das demonstrações financeiras utilizadas para a análise do presente estudo: a demonstração do resultado do exercício, o balanço patrimonial e a demonstração das origens e aplicações de recursos.

Em razão desses fatos, a companhia realizou alguns 


\subsection{Efeito dos incentivos fiscais nas demonstrações financeiras}

No período analisado, a empresa tem obtido resultados positivos a cada ano. Sua receita líquida de vendas apresentou crescimento ascendente, de 2002 para 2003, cresceu 40,51\% e em relação a 2004, 14,19\%.

Esses resultados e os ajustes promovidos nas demonstrações financeiras anteriormente explicitadas, repercutiram no lucro líquido apresentado pela empresa. A variação percentual em relação ao exercício de 2003, comparada ao de 2002 foi expressiva, cresceu 102,93\%. Em relação a 2004, houve um decréscimo do lucro, derivado, principalmente pelo aumento das despesas com vendas e do custo dos produtos vendidos.

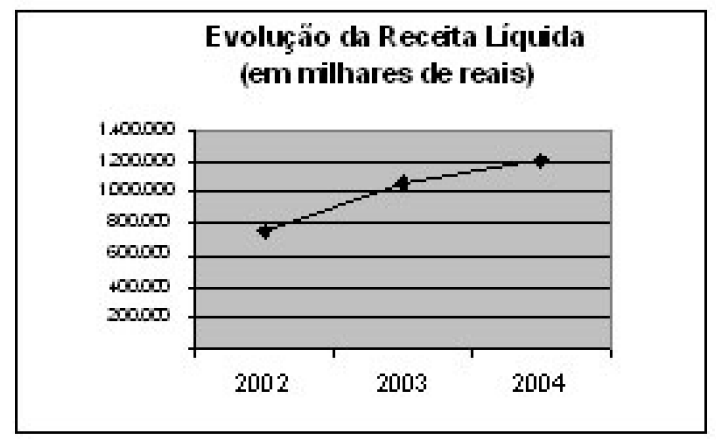

Gráfico 1: Evolução da Receita Líquida

Fonte: Grendene - Prospecto publicado em outubro 2004.

Partindo de uma análise vertical da DRE ajustada da empresa, mensurando-se o percentual dos incentivos fiscais em relação às principais contas da demonstração de resultado, têm-se os dados abaixo:

Tabela 1: Rubricas da DRE

\begin{tabular}{|c|c|c|c|}
\hline \multirow[t]{2}{*}{ Fubtio as da D RE } & \multicolumn{3}{|c|}{$\begin{array}{c}\text { Eremicio Social emetrado } \\
\text { em } 31 \text { de dezembro de }\end{array}$} \\
\hline & 2002 & 2003 & 2004 \\
\hline Reoeita Liquida de Tentas & $10,12 \%$ & $10,25 \%$ & $9,3,4 \%$ \\
\hline L.we L-iquido Ajustado & $65,21 \%$ & $45,75 \%$ & $56,10 \%$ \\
\hline
\end{tabular}

Fonte: Elaborado pelas autoras

Em consonância com Matarazzo (1997, p.257), que defende a idéia que a análise vertical atinge seu ponto máximo de utilidade quando aplicada à Demonstração de Resultado, os números acima indicam o valor percentual gerado pelos incentivos fiscais em relação às principais contas da DRE. Note-se que são bastante expressivos principalmente em relação ao lucro líquido, onde o percentual variou de 45 a $60 \%$ do valor total auferido nos anos em estudo.

O valor gerado somente pelos incentivos do FDI
(PROVIN e PROAPI) pode ser representado pelos dados expressos a seguir:

Tabela 2: Rubricas da DRE geradas pelos incentivos do FDI

\begin{tabular}{|c|c|c|c|}
\hline \multirow[t]{2}{*}{ Fubtioas da DRE. } & \multicolumn{3}{|c|}{$\begin{array}{l}\text { Erercioio } 5 \text { orial encertado } \\
\text { em } 31 \text { de deze mbeto de }\end{array}$} \\
\hline & 2002 & 2003 & 2004 \\
\hline $\begin{array}{l}\text { Reoeita Liquida de Tendas } \\
\text { Lworo Liquido Ajustado }\end{array}$ & $\begin{array}{l}6,96 \% \\
44,66 \%\end{array}$ & $\begin{array}{l}7,38 \% \\
32,92 \%\end{array}$ & $\begin{array}{r}7,69 \% \\
46,16 \%\end{array}$ \\
\hline
\end{tabular}

Fonte: Elaborado pelos autores

Em relação aos benefícios fiscais do FDI estes representaram a maior parcela dos números gerados na tabela acima, mostrando quão importantes são para a geração de resultados da empresa.

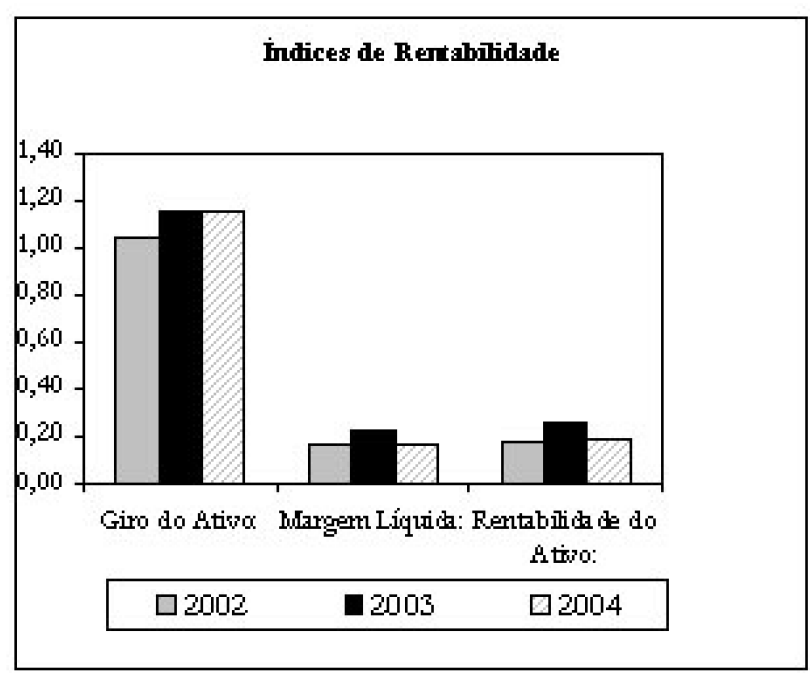

Gráfico 2: Índice de Rentabilidade

Fonte: Elaborado pelas autoras

Us indices de rentabilidade da empresa, extraidos da demonstração de resultado, apresentam-se satisfatórios. Comparando a mediana do setor de confecções, têxteis e calçados, extraída da revista Exame (2004), a margem de vendas apresentou índice de 1,6\% em 2003, enquanto a Companhia registrou uma média de $18 \%$, significando que a empresa auferiu de lucro para cada $\mathrm{R} \$$ 100,00 vendidos cerca de $\mathrm{R} \$ 18,00$. A taxa de rentabilidade do ativo, que mostra quanto a empresa obteve de lucro em relação ao ativo, representando a capacidade de geração de lucro da empresa, apresentou índices que variaram de 17 a $25 \%$, ou seja, de cada $\mathrm{R} \$ 100,00$ investidos a empresa ganhou cerca de $\mathrm{R} \$ 25,00$. Como esses índices são medidos em função do lucro líquido, pode-se inferir que os incentivos fiscais contribuíram de forma relevante para obtenção desses bons resultados.

Análises também podem ser feitas a partir de dados constantes da Demonstração das Origens e Aplicações de 
Recursos (DOAR). A análise vertical da DOAR mostra que na composição dos financiamentos os incentivos fiscais da empresa representam:

Tabela 3: Rubricas da DOAR

\begin{tabular}{|c|c|c|c|}
\hline \multirow[t]{2}{*}{ Fubtio as da DOAF } & \multicolumn{3}{|c|}{ 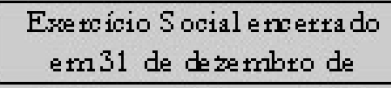 } \\
\hline & 2002 & 2003 & 2004 \\
\hline 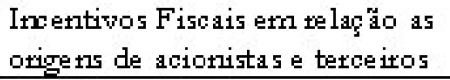 & $97,86 \%$ & $5,3,3 \%$ & $90,14 \%$ \\
\hline $\begin{array}{l}\text { Itwentivos Fisoais em telap to ao } \\
\text { total das oxidens }\end{array}$ & $54,65 \%$ & $29,68 \%$ & $50,95 \%$ \\
\hline $\begin{array}{l}\text { Lwo L.iquido em telapto ao } \\
\text { total das oxigetes }\end{array}$ & $83,80 \%$ & $5,5,83 \%$ & $30,45 \%$ \\
\hline
\end{tabular}

Fonte: Elaborado pelas autoras

Em conformidade com os números acima, com exceção do ano de 2003, os incentivos fiscais do imposto de renda e PROVIN / PROAPI representaram mais de $50 \%$ das origens de recursos da empresa. Em 2004, esse percentual é até mesmo superior ao valor representado pelo lucro líquido.

Em relação aos valores percentuais gerados apenas pelos incentivos PROAPI e PROVIN, estes chegaram a representar até cerca de $40 \%$ do valor total das origens de recursos para a série temporal estudada, como se vê:

Tabela 4: Rubricas da DOAR geradas pelos incentivos do FDI

\begin{tabular}{|c|c|c|c|}
\hline \multirow[t]{2}{*}{ Futations da DOAR } & \multicolumn{3}{|c|}{$\begin{array}{l}\text { Eneroisio Sorial enoextado } \\
\text { em } 31 \text { de dezembro de }\end{array}$} \\
\hline & 20102 & 2003 & 2004 \\
\hline 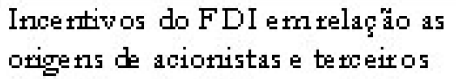 & $67,33 \%$ & $42,71 \%$ & $74,18 \%$ \\
\hline 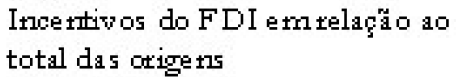 & $37,60 \%$ & $21,50 \%$ & $41,93 \%$ \\
\hline
\end{tabular}

Fonte: Elaborado pelas autoras

As parcelas não incentivadas, ou seja, os valores financiados que serão efetivamente pagos pela empresa após o período de carência constam nas demonstrações registrados no Balanço Patrimonial da empresa, nas rubricas passivo circulante e exigível a longo prazo.

Em 2002, esses valores estavam registrados da seguinte forma: $\mathrm{R} \$ 6.395$ milhões no passivo circulante e $\mathrm{R} \$ 52.354$ milhões no passivo exigível a longo prazo. Em 2003 houve um aumento do endividamento tendo sido registrado no balanço $\mathrm{R} \$ 13.881$ milhões no passivo circulante e R \$ 61.923 milhões no exigível a longo prazo. No passivo circulante e exigível relativos ao exercício de 2004, foram computados os valores de $\mathrm{R} \$ 15.029 \mathrm{mi}$ lhões e R $\$ 78.018$ milhões, respectivamente.

Apesar de ser uma das principais fontes de recursos da empresa, os incentivos fiscais não comprometem de maneira relevante o endividamento geral da empresa, que se manteve na faixa de $30 \%$, não dependendo esta exclusivamente de capital de terceiros, haja visa a consistência apresentada na geração de caixa operacional, proporcionando certa folga financeira, como pode ser observado nos dados a seguir, retirados do prospecto da empresa:

Tabela 5: Endividamento

\begin{tabular}{|c|c|c|c|}
\hline \multirow[t]{2}{*}{ EndividametIo } & \multicolumn{3}{|c|}{$\begin{array}{c}\text { Eretcic io Soc ial encetrado } \\
\text { emr } 31 \text { de dezembe de } \\
\text { (em mrillhate s de reais) }\end{array}$} \\
\hline & 2002 & 2003 & 2004 \\
\hline Divida Total & 210.966 & 132215 & 148.643 \\
\hline $\begin{array}{l}\text { Dispotribilidades e } \\
\text { Afilioaģöes } \\
\text { Fitraneiras }\end{array}$ & 211549 & 227.605 & 332774 \\
\hline $\begin{array}{l}\text { Divida Liquida } \\
\text { (Caira Liquido) }\end{array}$ & $(583)$ & $(95.390)$ & (184.131) \\
\hline
\end{tabular}

Fonte: Elaborado pelas autoras

A participação do capital de terceiros no patrimônio da entidade, o qual mostra quanto a empresa tomou de capital de terceiros em relação ao capital próprio investido revela-se da seguinte forma:

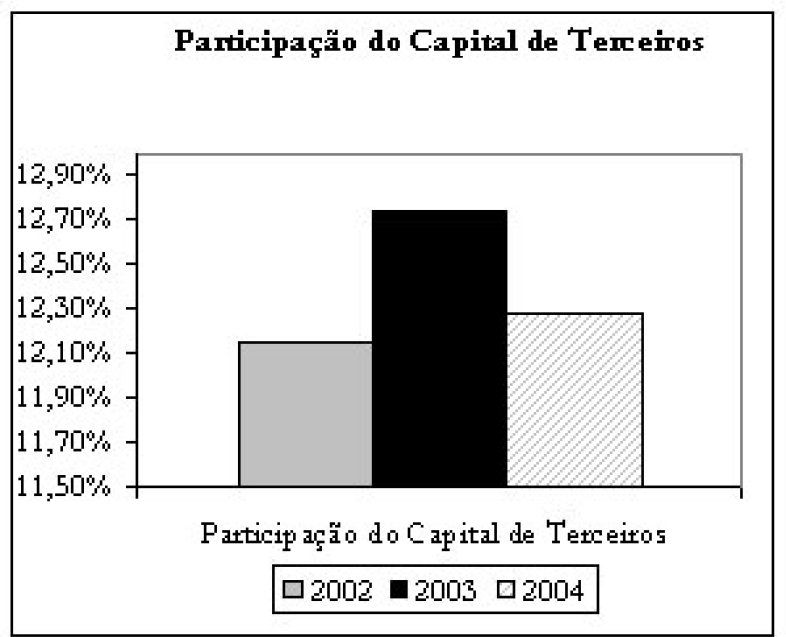

Gráfico 3: Participação do Capital de Terceiros

Fonte: Elaborado pelas autoras

A participação do capital de terceiros representado em sua maioria pelos financiamentos do FDI, mantevese estável ao longo dos anos, tendo aumentado sua participação em 2003 e 2004. Isto se deveu ao aumento do Patrimônio Líquido em função da contabilização dos incentivos fiscais na conta de reserva de capital.

A análise do balanço demonstra o grau de participa- 
ção dos incentivos fiscais nas contas do passivo (exigível e circulante).

Tabela 6: Rubricas do Balanço Patrimonial

\begin{tabular}{|c|c|c|c|}
\hline \multirow[t]{2}{*}{ Fubrio as do Balanȩo P attimotrial } & \multicolumn{3}{|c|}{$\begin{array}{l}\text { Exeroioio Social encextado } \\
\text { em } 31 \text { de dezembero de }\end{array}$} \\
\hline & 2002 & 2003 & 2004 \\
\hline 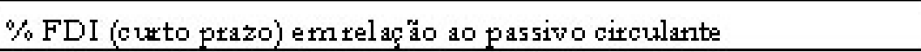 & $2,76 \%$ & $12,37 \%$ & $8,18 \%$ \\
\hline \% FDI (lotygo prazo) etrn telapa äo a exigiwel a longo ptazo & $98,60 \%$ & $52,72 \%$ & $60,48 \%$ \\
\hline \% FDI(cuto e lotgo prazo) etrn telap̧a a o total do endividamento & $20,28 \%$ & $33,01 \%$ & $29,75 \%$ \\
\hline
\end{tabular}

Fonte: Elaborado pelas autoras

Pelos valores expressos, vê-se que os valores financiados do FDI correspondem a cerca de 30\% do valor total do endividamento da empresa.

Os índices de liquidez, que buscam avaliar a situação financeira da empresa, apresentaram evolução. Isto porque houve um decréscimo do valor das dívidas de curto prazo de 2002 para 2003, sendo que em 2004 houve novo aumento. Se comparado a mediana apresentada pelo setor em 2003, que esteve no patamar de 1,78, os índices de liquidez da empresa apresentam-se satisfatórios, como mostra o gráfico abaixo:

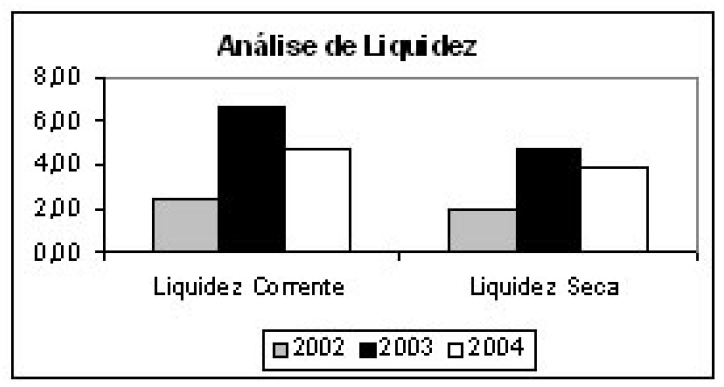

Gráfico 4: Análise de Liquidez

Fonte: Elaborado pelas autoras

Portanto, pelo acima exposto, pode-se inferir que a participação dos incentivos fiscais nos resultados da Grendene é relevante, influenciando diretamente o bom desempenho dos índices econômicos e financeiros ao longo do tempo.

A empresa está ciente disso, tanto que informa aos possíveis compradores de suas ações que uma eventual perda dos incentivos fiscais em vigor poderia causar efeitos adversos em seus resultados, sendo citado, inclusive, como um fator de risco para a empresa.

\section{CONCLUSÃO}

Este trabalho procurou mostrar a importância dos incentivos fiscais para as entidades beneficiárias e o efeito nos seus patrimônios, detalhando-se particularmente os incentivos fiscais decorrentes do Fundo de Desenvolvimento Industrial (FDI), do Governo do Estado do Ceará.

A política de incentivos fiscais do Ceará, primordialmente, viabilizada pelo FDI, tem se mostrado eficiente no sentido de ter efetivamente atraído várias empresas para o território cearense desde sua criação, contribuindo para a melhoria dos índices econômicos e impactando positivamente a geração de emprego e renda da região.

Entretanto, embora a política de atração de investimentos, instrumentalizada pelos incentivos fiscais-financeiros, tenha atingido números satisfatórios, alavancando o desenvolvimento do Ceará, sua forma de utilização tem sido alvo de críticas e foi sendo aperfeiçoada ao longo do tempo.

As discussões residiam no fato de que a concessão de incentivos inicialmente provocou fendas nas finanças públicas estaduais, haja vista o volume de renúncia fiscal devido principalmente à guerra fiscal, atingir índices superiores a sua capacidade de investimento. Esse quadro começou a mudar a partir de 2002, quando o FDI passou por grandes mudanças. Estabeleceram-se critérios para a concessão de incentivos fiscais, passando estes a serem geridos de maneira mais responsável e técnica, analisando-se, sobretudo, a relação custo-benefício para o Estado.

Nesse contexto, o presente trabalho procurou trazer à tona questionamentos quanto à importância dos incentivos fiscais para as empresas beneficiárias, ressaltando ainda a importância destas exercerem de maneira atuante ações no campo social, de forma a fazer valer a renúncia fiscal do governo.

Através da análise das demonstrações financeiras da empresa GRENDENE S.A, pode-se concluir que o impacto dos incentivos fiscais em seu patrimônio é relevante. Os incentivos fiscais, destacadamente os financiados pelo FDI, possuem efeitos substanciais na geração dos resultados. A própria empresa reconhece a eventual perda dos referidos incentivos como fator de risco para a continuidade de suas atividades.

Reconhecendo que o estudo teve como foco a análise de uma empresa, registra-se como sugestão de futuras pesquisas a aplicação da análise de um conjunto maior de empresas relativamente à utilização dos programas de incentivos fiscais do Estado, além da análise de outros índices econômicos e financeiros das empresas. Estudos adicionais poderão também contribuir com ajustes e melhorias das políticas de desenvolvimento econômico do Estado. 


\section{REFERÊNCIAS}

AMARAL FILHO, Jair do. Incentivos Fiscais e Políticas Estaduais de Atração de Investimentos. Texto para Discussão $\mathrm{n}^{\circ} 08$. IPECE. Ceará, 2003.

BRASIL. Constituição da República Federativa do Brasil. $20^{\mathrm{a}}$ ed. São Paulo: Saraiva, 1998.

Lei no 9.718 de 27 de novembro de 1998. Altera a legislação tributária federal. Disponível em <http:// www.planalto.gov.br>. Acesso em 12/04/2005.

CEARÁ. Governo do Estado. Lei no 10.367 de 07 de dezembro de 1979. Cria o Fundo de Desenvolvimento Industrial - FDI e dá outras providências. Disponível em <http:// www.sefaz.ce.gov.br>. Acesso em 15/04/2005.

. Decreto $n^{\circ} 27.040$ de 09 de maio de 2003. Consolida e regulamenta a legislação do Fundo de Desenvolvimento Industrial do Estado do Ceará - FDI. Disponível em <http:/ / www.sefaz.ce.gov.br>. Acesso em 15/04/2005.

. Lei $n^{\circ} 13.377$ de 29 de setembro de 2003. Altera os artigos $2^{\circ}$ e $5^{\circ}$ da lei 10.367 de 07 de dezembro de 1979. Disponível em <http://www.sefaz.ce.gov.br>. Acesso em 15/04/2005.

- Decreto $n^{\circ} 27.206$ de 07 de outubro de 2003. Regulamenta o caput do art. 20 da lei $\mathrm{n}^{\circ} 13.377$, de 29 de setembro de 2003, que disciplina a sistemática de apuração mensal do ICMS dos contribuintes inseridos no programa de incentivo ao desenvolvimento industrial - PROVIN / FDI, e dá outras providências. Disponível em <http://www.sefaz.ce.gov.br>. Acesso em 15/04/2005.

Decreto $n^{\circ} 27.470$ de 16 de junho de 2004. Ratifica e incorpora o convênio ICMS 104/02 e estabelece tratamento para cessão a título oneroso, dos direitos de recebimento do produto do adimplemento das prestações dos contribuintes do ICMS inseridos no Programa de Incentivo ao Desenvolvimento Industrial - PROVIN / FDI e dá outras providências. Disponível em <http://www.sefaz.ce.gov.br>. Acesso em $15 / 04 / 2005$.

CONFEDERAÇÃO NACIONAL DA INDÚstRIA. Políticas Estaduais de Apoio à Indústria. 123p. Rio de Janeiro, 1998.

CONSELHO FEDERAL DE CONTABILIDADE. Resolução CFC $n^{0} 1.026$ de 15 de abril de 2005. Aprova a NBCT T 19.4 - Incentivos Fiscais, Subvenções, Contribuições Auxílios e Doações. Disponível em < < t $\quad$ : // www.portaldecontabilidade.com.br>. Acesso em 27/05/ 2005.

DIAS, Francisco Régis Cavalcante; HOLANDA, Marcos Costa; AMARAL FILHO, Jair do. Base Conceitual dos Critérios para Concessão de Incentivos para Investimento no Ceará (FDI). Nota Técnica $n^{\circ}$ 03. IPECE. Fortaleza, Julho de 2003.

FEDERAÇÃO DAS INDÚSTRIAS DO ESTADO DO CEARÁ. A Extinção da SUDENE e uma Nova Política de Desenvolvimento do Nordeste. Disponível em: <http://www.fiec.org.br> Acesso em 23/02/2005.

GAZETA MERCANTIL. Balanço Anual 2003. Ano XXVII, $\mathrm{n}^{\circ} 27$, setembro/2003.

. Balanço Anual de 2004. Ano XXVIII, nº 28, Agosto/
GRENDENE. Disponível em <http:// www.grendene.com.br>. Acesso em 23/02/2005.

JORNAL O POVO; BOLSA DE VALORES REGIONAL. Prêmio Delmiro Gouveia. As Maiores e Melhores do Ceará 2004. $2^{\text {a }}$ ed. Encarte anexo à edição de 29 de abril de 2005 do Jornal O Povo.

MATARAZZO, Dante C. Análise Financeira de Balanços: Abordagem Básica e Gerencial. 4a ed. São Paulo: Atlas, 1997.

REVISTA EXAME. As 500 Maiores Empresas do Brasil. Ed Abril, Julho/2004.

ROCHA, Antônio Gláuter Teófilo. Velhos Instrumentos, Enfoque Inovador: Combinando Subsídios Fiscais e Desenvolvimento Local: O Caso do Ceará. Artigo no 05. IPECE. Disponível em <http://www.ipece.ce.gov.br>. Acesso em 23/01/2005.

ROCHA, Paulo Sérgio. Impacto das Renúncias Fiscais Federais nas Finanças Públicas dos Estados: O caso do Ceará. 2002. 103p. Dissertação (Mestrado em economia). Centro de pós-graduação em economia -CAEN, Universidade Federal do Ceará.

SECRETARIA DE DESENVOLVIMENTO ECONÔMICO (SDE). Guia do Investidor. Disponível em <http:// www.sde.ce.gov.br>. Acesso em 23/01/2005.

VARSANO, Ricardo. A Guerra Fiscal do ICMS: Quem ganha e quem perde. Texto para Discussão no 500. IPEA. Rio de Janeiro, 1997. 


\section{ANEXO A - DEMONSTRAÇÕES FINANCEIRAS \\ DA GRENDENE S.A.}

\section{GRENDENE S.A \\ DEMONSTRAÇÄO DO RESULT ADO DO EXERCÍCIO \\ (em milhares de reais)}

\section{Receita Bruta de Vendas e Serviços \\ Deduçốes de vendas \\ Receita Líquida devendas \\ Custó dos produtos vendidos \\ Lucro Brito \\ Receitas (despesas) operacionais \\ Com vendas \\ Geraise administrativas \\ Despesas financeiras \\ Receitas financeiras \\ Resultado de equivalência Patrimonial \\ Rerruneraçẩo dos administradores \\ Outras receitas operacionais \\ Outras despesas operacionais \\ Resultado operaciona \\ Resultado nẵo operacinal \\ Lucros antes dos impostos s/o lucroe \\ paticipaçáo dos minoritários \\ Provisẫo para o IRICGLL \\ Participaçẫo de Minoritärios \\ Lucro Líquido do Exercicio \\ GRENDENE S.A}

DEMONSTRAÇÃO DO RESULT ADO DO EXERCÍCIO

(em milhares de reais)

\section{Receita Bruta de Vendas e Serviços}

Deduçoses de vendas

Receita Líquida devendas

Custo dos produtos vendidos

Lucro Bruto

Receitas (despesas) operacionais

Com vendas

Geraise administrativas

Despesas financeiras

Receitas financeiras

Resultado de equivalência Patrimonial

Remuneraçẫo dos administradores

Outras receitas operacionais

Outras despesas operacionais

Resultado operaciona

Resultado nẫo operacinal

Lucros antes dos impostos s/o lucroe

participaça dos minoritários

Provisấo para imposto de renda

Participarẫo de Minoritários

Ajuste de beneficios fiscais

Lucro Líquido Ajustado

CONGOLIDADO

Exercicio Social encerrado em 31.12 .02

encerado em 31.12 .03

Exercicio Social

encerrado em 31.12.04

\begin{tabular}{rrr}
906.978 & $\mathbf{1 . 2 7 6 . 3 6 5}$ & $\mathbf{1 . 5 2 4 . 9 8 1}$ \\
$(151.792)$ & $(215.272)$ & $(313.363)$ \\
\hline $\mathbf{7 5 5 . 1 8 6}$ & $\mathbf{1 . 0 6 1 . 0 9 3}$ & 1.211 .618 \\
$(421.979)$ & $(542.978)$ & $(700.034)$ \\
\hline $\mathbf{3 3 3 . 2 0 7}$ & 518.115 & 511.584 \\
$(171.587)$ & $(217.310)$ & $(280.796)$ \\
$(46.017)$ & $(61.561)$ & $(65.996)$ \\
$(142.387)$ & $(126.917)$ & $(121.366)$ \\
95.411 & 84.351 & 51.772 \\
76.424 & 45.061 & \\
$(240)$ & $(240)$ & $(374)$ \\
10.652 & 3.413 & 13.544 \\
$(2.259)$ & $(3.051)$ & $(6.482)$ \\
\hline $\mathbf{1 5 3 . 2 0 5}$ & 261.971 & 101.886 \\
525 & $(203)$ & 71 \\
$\mathbf{1 5 3 . 7 3 0}$ & 261.668 & $\mathbf{1 0 1 . 9 5 7}$ \\
$(35.851)$ & $(57.826)$ & $(34.303)$ \\
$(717)$ & $(621)$ & \\
$\mathbf{1 1 7 . 1 6 2}$ & 203.221 & 67.654
\end{tabular}

CONGOLIDADO

Exercicio Social encerrado em 31.12 .03 encerrado em 31.12 .02

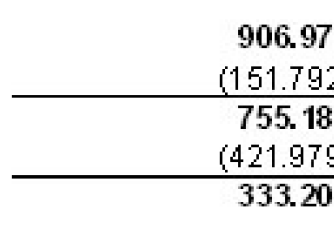

\begin{tabular}{rrr}
$(171.587)$ & $(218.773)$ & $(279.333)$ \\
$(46.017)$ & $(61.561)$ & $(65.996)$ \\
$(142.387)$ & $(137.797)$ & $(110.486)$ \\
95.411 & 84.351 & 51.772 \\
76.424 & 45.071 & \\
$(240)$ & $(240)$ & $(374)$ \\
10.652 & 23.413 & 13.544 \\
$(2.258)$ & $(5.764)$ & $(3.769)$ \\
\hline 153.205 & 232705 & 131.052 \\
525 & $(203)$ & 71 \\
\hline 153.730 & & 131.123 \\
$(35.851)$ & 232502 & $(43.749)$ \\
$(717)$ & $(57.926)$ & 1.228 \\
& $(621)$ & 113.203 \\
\hline 117.162 & 63.707 & 201.805 \\
& 237.762 & $\uparrow$
\end{tabular}

Exercicio Social encerrado em 31.12.04 
GREIIDEIIE S.A

\section{DEMOISTRAÇ̊O D O RE SULTADO DO EXERCícIO}

(em milhares de reais)

ATIVo
Circulante
Disponibilidades
Aplicaçö́es Financeiras
Contas a Receber
Estoques
Impostos a Recuperar
Titulos de Créditos a Receber
Creditos corm partes relacionadas
Outros créditos
IR e CSLL diferido
Despesas do exercicio seguintes

Total do Ativo Circulante

Realizável a Longo Prazo

Dividendo a receber

Depósitos judiciais

Irn postos a recuperar

Outros créditos
Exercicio Social encerrado em 31.12 .02
CONSOLIDADO

Exercicio Social

encerrado erm 31.12 .03 encerrado em 31.12 .04
Exercicio Social

\section{Permanente}

In'vetirmentos

Irm obilizado

\begin{tabular}{rrr}
18.916 & 29.310 & 23.534 \\
192.633 & 198.295 & 309.240 \\
230.253 & 302.186 & 369.764 \\
116.755 & 165.152 & 134.546 \\
10.641 & 14.157 & 7.023 \\
3.784 & 25.797 & 12.303 \\
& 293 & - \\
5.050 & 6.924 & 5.336 \\
& 306 & 9.713 \\
\hline 578.898 & 1.017 & 4.735 \\
\hline
\end{tabular}

Total do Ativo

\section{GREIIDEIIE S.A}

DEMOHSTRAÇÁO D O RE SULTADO DO EXERCícIO

\section{(em milhares de reais)}

\section{PASSIVO}

Circalante

Instituçốes Financeiras

Financiam ent 0 ( $P R O$ VIM e PROAPl)

Formecedores

Com issöes a P agar

IrT postos, taxas e contribuçốes

Sal arios encargos a pagar

Contas a pagar

Provisầo para oontigências

Dividendos propostos Irn posto de renda difirido Outras contas a pagar

Total do Passivo Circulante

\section{Exigivel a Longo Prazo}

Instituiçốes financeiras

Financiarm entos (PROVIM e PROAPI)

outras contas a pagar

Participaçấo Minoritária

\section{Patrimônio Líquido}

Capital Social realizado

Rieserva de reavaliaçẫo

Reserva de Capital

Reserva de lucros

Lucros acumtalados

\author{
Exercicio Social \\ encerrado em 31.12 .02
}

CONSOLIDADO

Exercicio Social

encerrado erm 31.12 .03
1.932

494

172

2.639

3.029

173.292

176.321

922.398 170.296

172.060

$\begin{array}{lll}726.663 & 922.398 & 1.050 .068\end{array}$

\begin{tabular}{rrr}
151.473 & 867 & \\
6.395 & 13.681 & 4.703 \\
25.551 & 25.525 & 15.029 \\
12.584 & 18.513 & 24.059 \\
6.910 & 11.643 & 20.311 \\
19.546 & 28.384 & 9.939 \\
2.734 & 6.271 & 34.258 \\
& - & 4.773 \\
& - & 450 \\
6.367 & 292 & 64.151 \\
231.560 & 6.629 & 253 \\
\hline
\end{tabular}

\begin{tabular}{rrr}
744 & 55.524 & 50.897 \\
52.354 & 61.923 & 78.014 \\
& - & 60 \\
\hline $\mathbf{5 3 . 0 9 8}$ & $\mathbf{1 1 . 4 4 7}$ & $\mathbf{1 2 8 . 9 9 9}$ \\
4.982 & & \\
& & 620.580 \\
131.600 & 137.477 & - \\
2.979 & 2.815 & 113.203 \\
- & 63.707 & 3.503 \\
26.320 & 27.495 & - \\
276.124 & 461.232 & $\mathbf{7 3 7 . 2 8 6}$ \\
\hline $\mathbf{4 3 7 . 0 2 3}$ & 692.726 & $\mathbf{1 . 0 5 0 . 0 6 0}$ \\
\hline 726.663 & 922.399 &
\end{tabular}




\section{GRENDENE S.A \\ DEMONSTRAÇÄO DO RESULTADO DO EXERCÍcIO \\ (emmilhares de reais)}

Das operaçồes:

Origens de Recursos
Exercicio Social encerrado em 31.12 .02
CONGOUDADO

Exercicio Social

encerrado em 31.12 .03
Exercicio Social encerrado em 31.12.04

Lucro Liquido do exercício

117.162

203221

67.654

tens que näo afetamo $0 \mathrm{LL}$ :

Eaixas de inwestimentos por wendaincorporaçäo

Eaixas do Permanente

Resultado de equivalência patrimonial

Depreciaçä̃o

Dos acionistase terceiros:

Aumento da participaçäo de minoritários

Incentw os fiscais de imposto de renda e

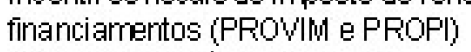

Ajuste de exerciciosanteriores

Fieduç âo do realic ável a longo prazo

Aumento do exigivel a longo prazo por incorporaça ão

Aumento do exigivel a longo prazo

Aumento do capital

Dividendos de controladas

Total das origens de recur sos

Aplicaçôes de Recursos:

Reduçẫo do exigivel a longo praxo

Participaçổes de minoritărios

Em investimentos

No permenente por incorporaçäo

No atiwo imobilizado

Diwidend as distribuidas

Dividendos prospostos para destribuiç âo

Total das aplicacioes de recursos

27.883

70.069

(76.424)

20.013

61.737

654

(45.071)

21.960

180.764

1.265

457

1.211

76.402

22

108.780

434

4.233

113.203

$-$

- $\quad 64.349$

- 5.877

64.349
5.877

11.552

183.259

364.022

125.583

139.000

401

20.777

18.501

67.562

72244

61.197

\section{Variaçäo do capital circulante:}

Ativo circularte

No fim do erercicio

No iní cio do exercício

Passivo circulante

No fim do exercicio

No irício do exercício

Aumento do capital circulante liquido

\begin{tabular}{rrr}
578.898 & 743.439 & 876.194 \\
347.880 & 578.898 & 743.439 \\
\hline 231.018 & 164.541 & 132.755 \\
& & \\
23.1560 & 112.225 & 183.783 \\
\hline 72.786 & 231.560 & 112.225 \\
\hline 158.774 & $(11.9335$ & 71.558 \\
\hline 72.244 & 283.876 & 61.197
\end{tabular}

43 CONTEXTUS Revista Contemporânea de Economia e Gestão. Vol.5 - No 1 - jan/jun/2007. (29-44). 
